Flower's survey of the requirements of the universities, and he agiain expressed his concern that our choice of priorities might be wrong. Lord Shorfield thought manned space rosearch was an oxample of the fields in which we could not compete. He urged that in the choice of priorities we should build on success and give priority in resources to advanced fields in which wo were either still in the lead or among the londers, instancing nuclear resoarch and technology: fusion research, radiochemistry, radio astronomy and important aroas of the biological sciences, as well as some sectors of aviation. He also emphasized the importance of international co-operation, either with single countries as with France in the Concord project, or with groups of countries as in the organizations already instanced. He suggested that some countries might tend to support their national programme rather than their share in an international programme to which thoy were also committed and for this roason he proferred a national effort. He thought our organization of research was soundly based, but regretted that the Industrial Research and Development Authority recommended by the Trend Committee had not been adopted; he believed that the establishment of a Ministry of Technology was a mistake.

Lord Todd also offered a warning against excessive commitment to space research and thought that the advantages coming from technological fall-out were exaggerated. Britain should either support technology with a definite economic aim or support primary scientific research rather than projects in which advantages were reaped from technological fall-out. She must beware of putting too much manpower into scientific research and too little of it into pursuit of technological ends; it was imperative that some hard choices be made which would lead to Britain opting out of some fields of science. He thought we would undoubtedly have to double our present expenditure on scientific research during the next five years, that is to say, there should be a gruwth rate of about 15 per cent per annum during that period; any cut in this would seriously endanger Britain's position as a leading nation.

\title{
EARNINGS OF CHEMISTS
}

$\mathrm{A}^{\mathrm{N}}$ article in Chemistry in Britain for October 1965 commenting on the remuneration survey, 1965 , conducted by the Royal Institute of Chemistry, gives some interesting comparisons of tho earnings of chomists with those of other professional people and scientists. Figures for 10 professions in 1964 are given by J. Graham in a series of articles for The Scotsman. Tho averago median earnings of chemists in Great Britain between the ages of 30 and 65 are shown by the survey as $£ 2,650$ in 1965 compared with $£ 1,600$ in 1956 . These figures comparo with figures for university teachers in 1964 and 1955 of $£ 2,350$ and $£ 1,500$, respectively. For ongineors the corresponding figures are givon as $£ 2,200$ and $£ 1,210$; for graduntes in industry $£ 2,575$ and $£ 1,570$; for doctors (consultants) $£ 4,000$ and $£ 3,130$, and for general practitioners, $£ 2,765$ and $£ 2,160$. Figures obtained in a survoy by the Institute of Physics in 1964 showed that salaries of its Fellows and Associates had rison by just over 72 per cont in the nine years from 1956, compared with a corresponding rise for chemists over the same poriod of 66.3 per cent. A typical Fellow of the Institute of Physics can oxpcet to reach a peak of $£ 3,400-£ 3,500$ a year, compared with $£ 3,100-£ 3,200$ for a Fellow of the Royal Institute of Chemistry. Looking at the earnings of chemists in various occupations, private industry no longer leads the field; its

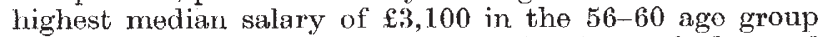
coming third, behind universities and colleges of advanced tochnology $(\mathfrak{f 3 , 4 6 0 )}$ and $f 3,150$ in the Atomic Energy Authority. Starting salaries in tho Scientific Civil Sorvice appoar to be outstandingly high, presumably because of more recruitment direct into the Senior Scientific Officer grade, and the subsequent prospects also soom to bo better than in most other categories of employment. This closing or narrowing of the gaps between median incomes in industry and those in other occupational catogories is particularly interesting in view of eurrent discussions on the possible shortage of scientists. It should be remembered, however, that chemists are not a particularly unified group and are engaged in a very wide range of diverse activities, which sometimes have only a tenuous connexion with their qualifications.

A further article in the November 1965 issue of Chemistry in Britain comments that chemistry appears to be about middlo of the professions surveyed and that it would appear that the median income levels in all the professions are tending to move closer together: a relatively small change of pace in relation to the general forward movement of incomes could drastically alter the position. Chemists atill do considerably better financially in some fields of employmont than in othors, but such differences also seem to be diminishing. The very low proportion of ehomists $(0.5$ per cent) roporting they were unemployed does not suggest a surplus, and of the 55 out of 10,459 without employment, only 29 had been out of work for more than 3 months, 13 of whom wore under 40 . While the earnings of older chemists have not increased suffciently to preserve the differential between them and their younger colleagues, the survey encourages the belief that most chemists whose employers regard them as 'too old at forty' have a good chance of finding one who does not. Tho survey also shows that any movement of chemists away from industry has been comparatively small, although most of the decline, from $59 \cdot 6$ per cont in 1956 to 55.5 per cent in 1964 , occurred in 1962-65.

\section{'O'-LEVEL EXAMINATIONS}

$\mathrm{F}^{\mathrm{o}}$ OUR years ago R. W. Crossland and R. Amos presented an analysis of ' $O$ '-lovel papers of tho Genernl Certificate of Education (G.C.E.) in biology of four Boards over the poriod 1948-59. The analysis was an attempt to quantify the omphasis placod on four main outcomos of biology teaching in the contents of the question papers.

Theso outeomes are: (1) the acquisition of facts, (2) the interpretation of facts and tho drawing of eonclusions from experiments, (3) the application of scientific principles to now situations, (4) the designing and planning of experiments.

Late in 1962 a similar analysis of the corresponding papers was unde for the period 1960-62 and more recently the analysis was brought up to date by including tho papers for 1963 and $1964 *$. The results of the three analyses are here shown separately, and, for comparison, the corresponding figures for the other science subjects aro also shown (Táble 1).

The analyses show the relative proportions of acquisition of facts and seientific method for the various sciences at ' $\mathrm{O}$ ' levol. Biology papors devote about 90 por cent of questions to facts. There are those who hold that one needs to know a good many biological facts before one can do much reasoning. The authors suggest that the Nuffeld Foundation Teaching Project and similar pro-

* Biol. Hum. Affairs, 36, №. 3 (1965). 
Table 1. Comparison of the Mean Percentages of Each Outcoue in Bhology, General Science, Chemistry and Physics Papers, 'O'-Inevet G.C.E. OF FOUR BOARDS, 1948-64

Welsh Cambridge Oxford

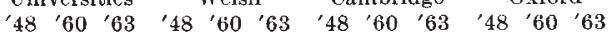

BIOLOGY

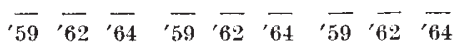

$\frac{48}{6-}, 63$

(1) Acquisition

of facts

(3) Application 110

GENERAL SCIENCE

(1) Acquisition $\quad 58 \quad 53 \quad 60$

(2) Interpretation $14 \quad 25 \quad 13$

(3) Application $\quad \begin{array}{lll}19 & 13 & 19\end{array}$

(4) Experimental $\begin{array}{rrr}8 & 9 & 8\end{array}$ CHEMISTRY

(1) Acquisition

(2) Interpretation $\begin{array}{rrr}8 & 9 & 3\end{array}$

(3) Application $\quad \begin{array}{lll}17 & 11 & 16\end{array}$ PHysics

(1) Acquisition $\quad 43 \quad 41 \quad 54$

(3) Application $\quad 38 \quad 36 \quad 38$

(4) Experimental $12 \quad 14$
5
$9-12$

$8-3$

$\begin{array}{lll}59 & 53 & 60\end{array}$

$\begin{array}{rrr}4 & 10 & 1 \\ 11 & 18 & 32\end{array}$

$\begin{array}{lll}26 & 20 & 7\end{array}$

$40 \quad 36 \quad 36$

$\begin{array}{rrr}5 & 7 & 2\end{array}$

$\begin{array}{rrr}39 & 50 & 58\end{array}$

$\begin{array}{rrr}16 & 9 & 4\end{array}$
$78-82$ $\begin{array}{lll}59 & 62 & 64\end{array}$

$\begin{array}{rrr}84 & 89 & 91 \\ 0 & 1 & 5\end{array}$

1574

$\begin{array}{lll}68 & 63 & 70\end{array}$

$\begin{array}{rrr}7 & 9 & 7\end{array}$

$\begin{array}{rrr}12 & 19 & 18\end{array}$

$\begin{array}{lll}13 & 10 & 5\end{array}$

\begin{tabular}{lll}
$48 \quad 48 \quad 6$ \\
\hline
\end{tabular}

$12-$

$\begin{array}{lll}12 & 37 & 25\end{array}$

$\begin{array}{lll}28 & 16 & 11\end{array}$

$\begin{array}{lll}39 & 34 & 30\end{array}$

$310 \quad-$

$\begin{array}{lll}34 & 45 & 62\end{array}$

$\begin{array}{rrr}34 & 45 & 62 \\ 25 & 12 & 8\end{array}$ $\begin{array}{lll}0 & 1 & 5 \\ 1 & 4 & 0\end{array}$

85

$\begin{array}{rrr}0 & 7 & 7\end{array}$

$\begin{array}{lll}4 & 3 & 3\end{array}$

$\begin{array}{lll}12 & 6 & 5\end{array}$

6671

$6 \quad 10-$

$15 \quad 16$ -

144

$\begin{array}{lll}64 & 57 & 57\end{array}$

522

$\begin{array}{lll}14 & 21 & 26\end{array}$

$\begin{array}{lll}17 & 20 & 15\end{array}$

$\begin{array}{lll}40 & 52 & 46\end{array}$

$\begin{array}{lll}5 & 4 & 2\end{array}$

$\begin{array}{lll}38 & 33 & 45\end{array}$
(2) Interpretation $\quad 78 \quad 84 \quad 93$

$\begin{array}{llllll}2 & 1 & 2 & 0 & 0 & 0\end{array}$ teach young pupils an understanding of the nature of the scientific process.

To-day the goal of mastering the factual content of a subject is not sufficient; there are other goals and needs at all levels of learning. The teaching of facts and method may go hand in hand. It is how the facts are learned and organized that makes a difference. Science is most effectively taught and learned when both pupils and teacher practise scientific investigation-when they devise experiments to solve problems and improvise simple apparatus for carrying them out.

One would expect general science, chemistry and physics papers to have smaller percentages of factual questions, because it has long been the standard practice in the teaching of physical sciences to apply scientific principles in numerical problems. About 20 per cent of the general science and chemistry papers and 40 per cent in physics are devoted to 'Application'. But, in general, these problems are formal and stereotyped and amount to little more than a memory test. There is no real, new scientific problem to solve.

About 20 per cent of chemistry papers and slightly less percentages in the other scientific subjects deal with experimental work. Hore again, this is rarely more than memory work, dealing with hoary experiments and demonstrations which have been thoroughly rehearsed. Rarely is a candidate expected to show imagination and ingenuity in devising oxperiments to test hypotheses which are new to him.

In their article, Crossland and Amos provide further evidence to show that sciontific method is virtually ignored in ' $O$ '-level science courses. They discuss the implication of this deficiency for the education of all pupils and make suggestions for a shift in emphasis from mere memory work towards some appreciation of scientific methods in ' $\mathrm{O}$ '-level examinations.

The syllabuses in biology, general science, chemistry and physics of the nine General Certificate of Education Examining Boards were also examined. Apart from one Board, the Oxford and Cambridge, references to scientific method in biology, chemistry and physics are limited. In biology they are confined to a training in observation and recording; "Biological knowledge should be based-on observation of living plants and animals both in the laboratory and out of doors" is typical. Practical work in physical sciences is meant to give a training in skills and techniques, and in carrying out directions. In general science there are clearer signs that scientific method should be taught; for example, in the Cambridge syllabus we read " . . . the student should be led to some appreciation of scientific principles and methods by which they have been established". But the one Board which comes nearest to the treatment of scientific method is the Oxford and Cambridge. In its biology syllabus it states: (1) ". . (candidates) expected to draw conclusions from simple experiments which they perform". (2) "... to understand the necessity for control experiments". (3) "... questions ... which test powers of observation and reasoning of candidates". The general conclusion to be drawn from a study of the syllabuses is that only a limited amount of scientific method is expected a.t ' $\mathrm{O}$ '-level.

\section{FUEL UTILIZATION}

$\mathrm{F}^{\mathrm{T}}$ UEL utilization is often regarded as the Cinderella of industry. Industries such as aircraft, motor cars, electronics and computers regard the designers of combustion chambers, boilers and furnaces as belonging to a comparatively primitive and unenterprising sector of industry. Such a view is only justified to the extent that the very small profit margins of old-established industries, which were in existence at the very beginning of the industrial revolution, allow only a small fraction of their annual turnover to be spent on research and development. In the case of units such as power station boilers or blast furnaces, each of which costs hundreds of thousands, if not millions, of pounds, the difficulties of developing a radically new and better design are immense, and unless there is a co-ordinating national development programme it is impossible to undertake the development of a greatly improved new type of appliance. Work with small pilot plant for such a new idea costs tens of thousands of pounds, and work with large pilot plant, which is essential to give answers to the economic questions of capital cost, reliability and required quality of constructional materials, costs in the range of hundreds of thousands of pounds.

It is, therefore, particularly timely and of national importance that the Institute of Fuel should have devoted the whole of a four-day conference to fuel research and development*.

The first paper in the conference was a directory of organizations carrying out research and development. This covers industrial firms and research organizations of the fuel industries, and ranges from small individual burner-makers up to organizations like Imperial Chemical Industries, Ltd., and Shell. Strangely enough, it does not, however, include any work done by universities and technical colleges, a number of which are doing valuable work at the small pilot plant and bench scale stages of applied research. The authors of the directory conclude that about 2,900 graduates and 5,000 non-graduates are working in the organizations covered by their survey and that the annual expenditure on fuel research and development excluding nuclear energy is just under $£ 20$ million. If we take it that the national annual fuel bill is of the order of $£ 2,000$ million, this comes out at 1 per cent, a very much lower figure than would be found in the more rapidly changing industries.

The first main session of the conference dealt with the organization of a research department, and the papers covered a number of interesting points, including Fronch,

* Institute of Fuel. Proceedings at the Conference on Fuel Research and Development held at Eastbourne, 4th to 8th October, 1965. Vol. $1:$ Papers. Jp.
294. Comference Handbook. Pp. 14. (London: The Institute of Fuel, 1965.) 